\title{
AÇÃO DO LASER DE BAIXA INTENSIDADE NA PRODUÇÃO DE METABÓLITOS SECUNDÁRIOS DO DERMATÓFITO TRICHOPHYTON RUBRUM
}

\section{ACTION OF LOW INTENSITY LASER ON THE PRODUCTION OF SECONDARY METABOLITES OF TRICHOPHYTON RUBRUM}

\author{
Idália Aparecida Waltrick de Brito Siqueira ${ }^{1}$ \\ Milton Beltrame Junior ${ }^{2}$ \\ Maria Belén Salazar Posso ${ }^{3}$ \\ Newton Soares da Silva ${ }^{4}$
}

RESUMO: A ação do laser arseneto de gálio alumínio (GaAlAs), nos comprimentos de onda 685nm e 830nm em cultura de Trichophyton rubrum, foi estudada visando a obter os metabólitos secundários e avaliar a sua citotoxicida-de em cultura de células. Foram utilizadas cepas do dermatófito T. rubrum, provenientes do laboratório de Microbio-logia da Universidade do Vale do Paraíba. O cultivo foi realizado em meio de cultura sólido de ágar Sabouraud (Merck, Alemanha) em placa de Petri. A colônia de T. rubrum foi irradiada com o laser (GaAlAs) a uma distância de $1 \mathrm{~cm}$ da placa e incubada em estufa $26^{\circ} \mathrm{C}$. Para o ensaio de citotoxicidade, foi utilizada a linhagem celular L929 (tecido conjuntivo de camundongo), proveniente do laboratório Adolf Lutz, de São Paulo. As células foram plaquea-das e incubadas com o extrato fúngico em diferentes concentrações, por uma hora. Após essa incubação, foi realizado o teste de Metil tiazol tetrazólio (MTT) para avaliação da citotoxicidade. Obteve-se uma diferença no crescimento das colônias-controle e irradiadas a $685 \mathrm{~nm}$ estatisticamente significante $(p<0,05)$. Na análise estatística comparativa da citotoxicidade causada pelos extratos nas concentrações $2,5 \mathrm{mg} / \mathrm{ml}$ e $25 \times 10^{-6} \mathrm{mg} / \mathrm{ml}$, foi obtido $p<0,05$, o mesmo ocorreu entre as concentrações $25 \times 10^{-2} \mathrm{mg} / \mathrm{ml}$ e $25 \times 10^{-6} \mathrm{mg} / \mathrm{ml}$. Na concentração de $25 \times 10^{-2} \mathrm{mg} / \mathrm{ml}$, observa-se uma elevação considerável (78,55\%) na atividade mitocondrial dos grupos com tratamento, em relação ao controle. $O$ laser GaAlAs, nas condições metodológicas deste estudo, apresentou efeitos no metabolismo celular, alteração de morfologia e da taxa de crescimento da colônia in vitro. $O$ extrato fúngico das colônias irradiadas apresentou efeito bioestimulador quando comparado ao extrato obtido do grupo controle e sem tratamento com laser.

Palavras-chave: laser; Trichophyton rubrum; citotoxicidade.

ABSTRACT: The action of aluminum gallium arsenide laser (GaAlAs), at wavelengths of $685 \mathrm{~nm}$ and $830 \mathrm{~nm}$ was studied to obtain the secondary metabolites and to evaluate the cytotoxicity in cell culture of Trichophyton rubrum. Strains of the dermatophyte T. rubrum were used from the microbiology laboratory at the Universidade do Vale do Paraíba. The culture was grown in solid medium Sabouraud agar (Merck, Germany) in Petri dishes. The colony of T. rubrum was irradiated with the laser (GaAlAs) at a distance of $1 \mathrm{~cm}$ from the plate and incubated at $26^{\circ} \mathrm{C}$. For the cytotoxicity assay, the cell line $L 929$ (mouse connective tissue) from the Adolfo Lutz laboratory in Sao Paulo was used. Cells were plated and incubated with the fungal extract in different concentrations for $1 \mathrm{~h}$. After this incubation, methyl thiazol tetrazolium (MTT) testing was performed to evaluate cytotoxicity. The difference in growth of the control and the colony irradiated at $685 \mathrm{~nm}$ was statistically significant $(p<0.05)$. In comparative statistical analysis of the cytotoxicity caused by the extracts at concentrations of $2.5 \mathrm{mg} / \mathrm{ml}$ and $25 \times 10^{-6} \mathrm{mg} / \mathrm{ml}$, $p<0.05$ was obtained, and the same occurred between $25 \times 10^{-2} \mathrm{mg} / \mathrm{ml}$ and $25 \times 10^{-6} \mathrm{mg} / \mathrm{ml}$ concentrations. At the concentration of $25 \times 10^{2} \mathrm{mg} / \mathrm{ml}$, a significant increase (78.55\%) was observed in mitochondrial activity of treated groups compared to control. The GaAlAs laser, under the methodological conditions of this study, affected cell metabolism, changed morphology, and altered the rate of colony growth in vitro. The extract of irradiated fungi had a biostimulative effect compared with the extract obtained from fungi without laser treatment.

Keywords: laser; Trichophyton rubrum; cytotoxicity.

\footnotetext{
${ }^{1}$ Doutoranda em Engenharia Biomédica - Universidade do Vale do Paraíba - Univap. E-mail: idaliasiqueira@yahoo.com.br. ${ }^{2}$ Doutor em Química - Universidade de São Paulo - USP e Professor Integral da Univap. E-mail: beltrame@univap.br.

${ }^{3}$ Doutora em Enfermagem - Universidade de São Paulo - USP e Professora Integral da Univap. E-mail: mbelen@terra.com.br.

4 Doutor em Biociências e Biotecnologia - Universidade Estadual do Norte Fluminense Darcy Ribeiro - UENF e Professor Integral da Univap. E-mail: nsoares@univap.br.
} 


\section{INTRODUÇÃO}

Toda e qualquer micose se inicia pela infiltração no hospedeiro, de um fungo apto ao parasitismo. Os fungos estabelecem processos que diversificam em extensão e em tipo anatomopatológico (LACAZ et al., 2002).

O aumento de casos de micoses constitui um relevante problema de saúde pública, que afeta grande parte da população mundial, podendo comprometer a qualidade de vida (RODRIGUES, 2007).

Os dermatófitos possuem a capacidade de afetar tecidos queratinizados de humanos e outros animais, como pele, pêlos e unhas (WEITZMAN; SUMMERBELL, 1995), utilizando-os como material nutritivo. Mas, por outro lado, geram elastases, que Ihes permitem conduzir-se sobre a elastina, o que também auxilia na sua instauração (TRABULSI et al., 1999). No tecido cutâneo, normalmente os dermatófitos provocam lesões descamativas arredondadas, com eritemas nas bordas, com tendência à cura central. As unhas adquirem coloração branca amareladas com aspecto poroso e quebradiço (MARCHISIO; PREVE; TULLIO, 1996).

Os dermatófitos são classificados em três gêneros: Trichophyton, Microsporum e Epidermophyton, semelhantes em sua morfofisiologia, imunologia e taxonomia (LACAZ; MARTINS; PORTO, 1991; REZENDE et al., 2008; SANTOS; SAMPAIO; PINHEIRO, 2006). Trichophyton rubrum é um fungo filamentoso que infecta os tecidos queratinizados, como pele, cabelos e unhas, é o agente mais comum de dermatomicoses do mundo (ALY et al., 2001; ARENAS; DOMINGUEZ-CHERIT; FERNANDEZ, 1995; ELEWSK, 2000; NWEZE, 2001).
Lacaz et al. (2002) relatam, em estudo in vitro, que, ao examinar o $T$. rubrum diretamente do material clínico, nota-se a presença de hifas septadas hialinas. As colônias de coloração branca e textura algodonosa, com pregas radiais na vista frontal e no reverso pigmentadas de vermelho, apresentaram crescimento lento (CERVELATTI et al., 2004).

Os tratamentos para dermatomicoses constituem em debridamento químico e mecânico, tratamento farmacológico antifúngico tópico e sistêmico, ou uma associação de ambos. Essas opções de tratamento nem sempre são satisfatórias devido ao alto custo e eficácia ( $\mathrm{FINCH}$; WARSHAW, 2007). Os efeitos colaterais das medicações e a dificuldade de aplicação de medicações tópicas são fatores que comprometem o tratamento (LESHER, 1999; KOEHLER; MAIBACH, 2001).

A persistência de uma infecção fúngica não é rara e resulta em altos custos com o tratamento (ELEWSKI, 2000; JOISH; ARMSTRONG, 2001; SCHER, 1999). Os antifúngicos sistêmicos são considerados mais eficazes apesar do período longo, porém estudos demonstraram um elevado número de casos de recidiva após cinco anos de tratamento (SIGURGEIRSSON et al., 2002; TOSTI et al. 1998). Pode ocorrer uma melhora do quadro clínico durante o tratamento, uma falsa cura que pode ser a causa de interrupção do tratamento (ZAITZ et al., 1998).

Segundo Sabino, Inomata e Lamarco (1982), certos fungos são aptos a gerar metabólitos secundários que são tóxicos e algumas vezes, cancerígenos para o ser humano.

Os laseres de baixa intensidade têm sido utilizados na área de saúde, para o 
tratamento clínico de processos inflamatórios, na biomodulação celular e alívio da dor, devido ao seu efeito antiinflamatório, na melhora da regeneração tecidual (BORATO et al., 2008; ROCHA, 2003; SILVEIRA; NICOLAU, 2007), e pesquisas in vitro recentes têm enfatizado o uso do laser de baixa intensidade para o tratamento de dermatomicoses. Alguns autores relataram uma inibição significativa do crescimento do T. rubrum após a laserterapia (VURAL et al., 2008; KOZAREVE; VIZINTIN, 2010; MANEVITCH et al., 2010).

Porém, há uma escassez de pesquisas sobre 0 efeito do laser no tratamento de dermatomicoses, fazem-se necessários estudos que enfatizem a ação do laser em microrganismos (HEES; RAULIN; BÄUMLER, 2012). Nesse sentido, esta pesquisa objetiva verificar se o laser GaAlAs de baixa intensidade, emitindo no vermelho visível $685 \mathrm{~nm}$ e no infravermelho $830 \mathrm{~nm}$, influencia no crescimento e na produção de metabólicos secundários do $\mathrm{T}$. rubrum, além de verificar os efeitos desses metabólitos secundários em cultura de células L929.

\section{MATERIAL E MÉTODOS}

Foram utilizadas cepas do dermatófito T. Rubrum, provenientes do laboratório de Microbiologia da Universidade do Vale do Paraíba.

\subsection{Método de cultivo}

O cultivo do T. rubrum foi realizado em meio de cultura sólido de ágar Sabouraud (Merck Alemanha), dextrose 4\% em placas de Petri.

O repique do fungo foi realizado com o auxílio de uma alça em $\mathrm{L}$, por meio da remoção de um pedaço de área de $1 \mathrm{~cm}^{2}$, com formato quadrado da borda distal do halo, de uma colônia crescida por nove dias. Esse pedaço foi utilizado como inóculo para placas contendo o mesmo meio. Para isso, ele foi colocado no centro dessas placas, as quais foram incubadas por 15 dias a $26{ }^{\circ} \mathrm{C}$, com pouca luz. Nove placas foram inoculadas a partir de uma única placa mãe.

\subsection{Método de irradiação}

As placas foram identificadas e nomeadas para a realização do experimento, sendo três placas para o grupo controle, três para o grupo irradiado a 685 $\mathrm{nm}$ e três para o grupo irradiado a $830 \mathrm{~nm}$.

Para a irradiação, foi utilizado o aparelho Thera lase ${ }^{\circledR}$ (DMC, Ribeirão Preto, Brasil), com emissão na região visível (685 $\mathrm{nm})$ e na região infravermelha $(830 \mathrm{~nm})$ do espectro eletromagnético. Ambos os comprimentos de onda apresentavam os mesmos parâmetros de irradiação: potência de $35 \mathrm{~mW}$, irradiação por fibra óptica de $600 \mu \mathrm{m}$, densidade de potência de $0,04 \mathrm{~W} / \mathrm{cm}^{2}$, densidade de energia (fluência) de $4 \mathrm{~J} / \mathrm{cm}^{2}$, tempo de irradiação de $1 \mathrm{~min}$ e 55s e energia de 4,6J. A colônia de $T$. rubrum foi irradiada com o laser (GaAlAs) a uma distância de $1 \mathrm{~cm}$ da placa e incubadas em estufa $26{ }^{\circ} \mathrm{C}$ e o crescimento foi observado diariamente.

\subsection{Método de mensuração da colônia}

O crescimento do T. rubrum irradiado, ou não, foi mensurado diariamente durante 
15 dias. A mensuração foi realizada com régua metálica milimetrada, com variação de 0,5mm, devido à imprecisão desse instrumento de medida.

Os aspectos macroscópicos das colônias foram registrados com o uso de uma câmera digital (SONY/Cyber-shot DSCP93A), no 15ํ dia após a irradiação.

\subsection{Método de extração dos metabólitos}

O método de extração foi realizado conforme descrito por Gupta (2000). As culturas de $T$. rubrum irradiadas ou não foram extraídas, por meio de maceração, em $100 \mathrm{ml}$ da solução de metanol, clorofórmio e ácido acético, na proporção de 50:50:1 ( $\mathrm{vol} / \mathrm{vol} / \mathrm{vol})$. O extrato foi filtrado em lã de vidro e, posteriormente, submetido à evaporação rotativa à baixa pressão. $O$ resíduo oleoso obtido foi extraído com $50 \mathrm{ml}$ de acetonitrila, por 5 minutos, e filtrado em lã de vidro. O solvente foi removido por evaporação rotativa à baixa pressão a $40^{\circ} \mathrm{C}$. O resíduo seco obtido foi misturado com $5 \mathrm{ml}$ de acetonitrila no vórtex. Posteriormente, foi seco em estufa a $30^{\circ} \mathrm{C}$ por $72 \mathrm{~h}$, pesado e armazenado em frascos de vidro protegidos da luz.

\subsection{Método de ensaio Metil tiazol tetrazólio (MTT)}

Foram utilizadas células da linhagem celular L929 (tecido conjuntivo de camundongo), provenientes do Laboratório Adolf Lutz, São Paulo. O meio de cultura utilizado foi o Meio Mínimo Essencial (MEM) adicionado 10\% Soro Fetal Bovino (SFB). As células foram descongeladas e mantidas em garrafas de culturas, em estufa, a $37{ }^{\circ} \mathrm{C}$, com atmosfera de $5 \%$ de $\mathrm{CO}_{2}$. Para testes com o extrato fúngico, as células foram tripsinizadas e plaqueadas em placas de cultura de 96 poços e incubadas novamente na estufa por 24h, para adesão.

O extrato fúngico dos grupos irradiados ou não foi diluído em Dimetil Sulfóxido (DMSO) sob agitação manual, onde a concentração final dos extratos foi de $25 \mathrm{mg} / \mathrm{ml}$. As células L929 plaqueadas foram ensaiadas com os extratos. O meio de cultura de cada poço foi removido e foram adicionados $180 \mu$ l de Tampão salino-fosfato (PBS). Foram adicionadas, então, $20 \mu \mathrm{l}$ dos extratos no primeiro poço, e realizada uma diluição seriada. Células sem adição dos extratos (somente com $200 \mu$ l de PBS) foram utilizadas como controle. Em seguida, as placas foram incubadas, em estufa, a $37^{\circ} \mathrm{C}$ com atmosfera de $5 \%$ de $\mathrm{CO}_{2}$ por $1 \mathrm{~h}$. Após esse período, a solução de PBS (com ou sem extrato) foi aspirada e descartada. Foram, então, adicionados $200 \mu \mathrm{l}$ da solução de MTT em todos os poços da placa de cultura, a qual foi incubada novamente.

Após o período de uma hora, a solução de MTT foi aspirada e descartada e foram adicionados $200 \mu \mathrm{l}$ de DMSO em todos os poços. Em seguida, a placa foi agitada por $30 \mathrm{~min}$, a $37{ }^{\circ} \mathrm{C}$, e levada ao espectrofotômetro (SpectraCount, Packard), para leitura a $570 \mathrm{~nm}$.

\subsection{Método de análise}

Os resultados foram digitados $e$ tabulados eletronicamente, analisados quantitativamente e representados em forma de gráficos. Para análise descritiva e de correlação dos dados obtidos, foi utilizado o programa Microsoft Excel® 2007 e Origin versão 7.0 para o cálculo das médias e desvios-padrão de todas as variáveis anali- 
sadas, que serão apresentados em forma de gráficos. Para comparar as médias das variáveis e identificar se existiam diferenças estatisticamente significativas entre os grupos, os ensaios foram analisados por ANOVA, seguidos de Tukey, utilizando-se o software Bioestat 5.0. O nível de significância utilizado foi $p<0,05$ (VIEIRA, 1991).

\section{RESULTADOS}

Após o acompanhamento das colônias, foram constatadas alterações de crescimento, topografia, textura e pigmentação.

Em média, as colônias irradiadas, com $685 \mathrm{~nm}$ e $830 \mathrm{~nm}$, apresentaram taxa de crescimento superior quando comparado com o grupo controle. Ambas superaram uma diferença no crescimento de $29,2 \%$ e $16,0 \%$, respectivamente, ao final de 15 dias (Fig. 1). Observa-se uma diferença no crescimento das colônias-controle e irradiadas a $685 \mathrm{~nm}$ com significância estatística $(p<0,05)$.

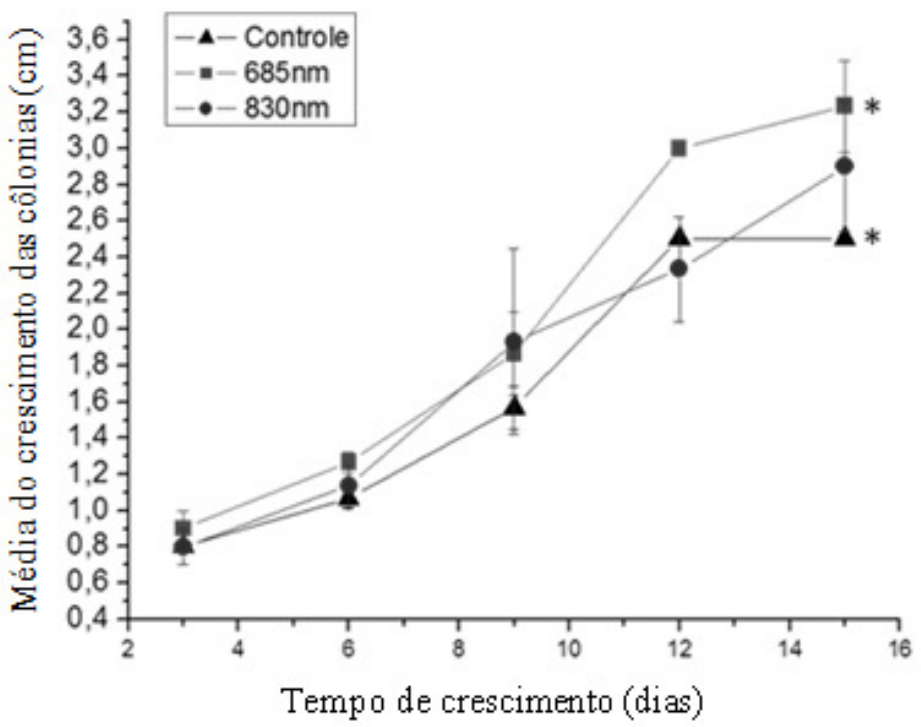

Fig. 1 - Crescimento das colônias. $O$ diâmetro de cada colônia foi mensurado com uma régua e o resultado é dado em centímetros por dia de cultura como média e desvio padrão de triplicatas. ${ }^{*} p<0,05$.

As culturas de $T$. rubrum das placas- algodonosa, com infiltração no meio de controle apresentaram os aspectos cultivo, e bordas regulares (Fig. 2). No característicos de cultura para esse reverso da colônia, foi observada microrganismo, como coloração branca, pigmentação castanha no centro e coloração região apicular no centro, textura amarela nas bordas (Fig. 3). 


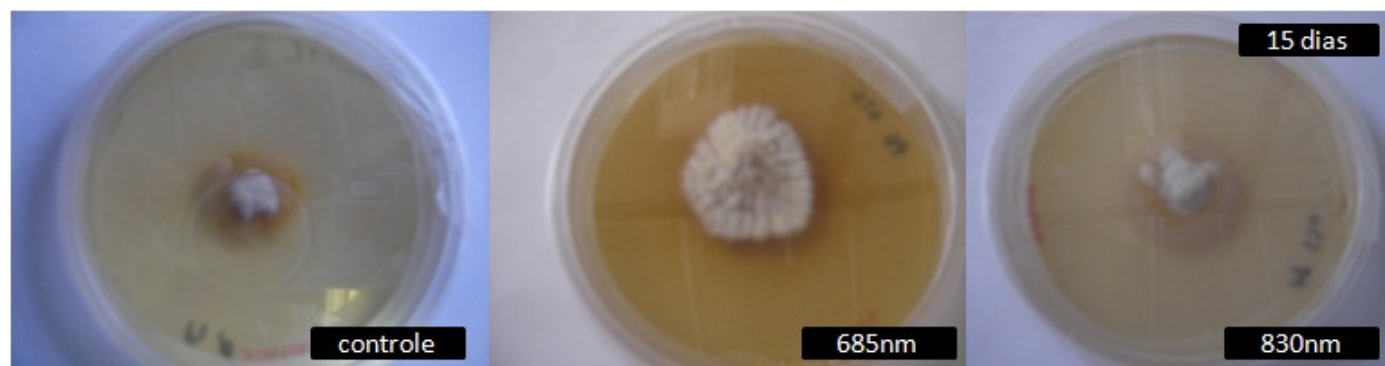

Fig. 2 - Frente das colônias de T. rubrum do grupo controle e irradiados após 15 dias de incubação.

No comprimento de onda de irradiação de $685 \mathrm{~nm}$, as colônias apresentaram aumento de crescimento, maior desenvolvimento da região apicular, hiperpigmentação castanho claro no reverso e textura frontal veludosa (Figs. 2 e 3).

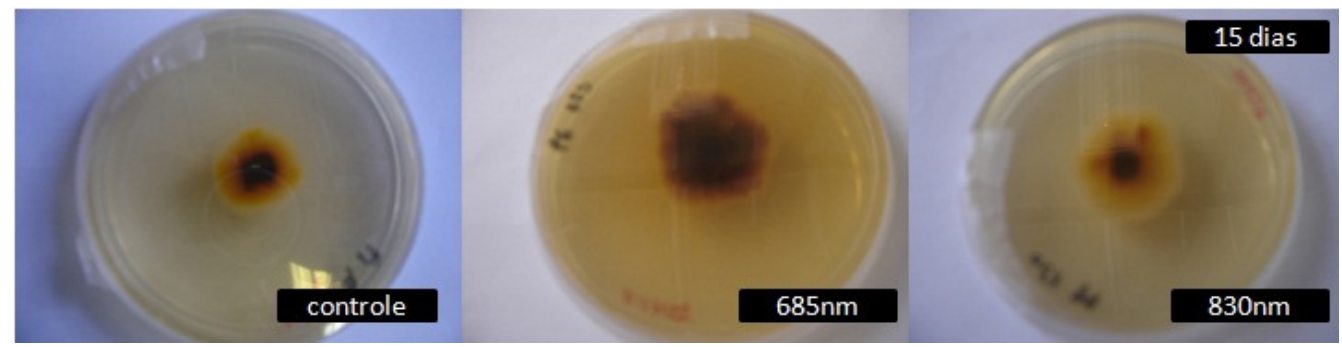

Fig. 3 - Reverso das colônias de T.rubrum do grupo controle e irradiados após 15 dias de incubação.

No comprimento de onda de $830 \mathrm{~nm}$, apicular obteve maior desenvolvimento em as colônias apresentaram uma alteração de relação ao das colônias-controle e ao das textura e pigmentação, com características irradiadas a $685 \mathrm{~nm}$. No reverso da colônia, mistas. A coloração foi branca e a textura observou-se hiperpigmentação castanho veludosa na região do contorno apicular, escuro e amarelo nas bordas, conforme (Fig. transparente e membranosa nas bordas 3). irregulares da colônia (Fig. 2). A região 


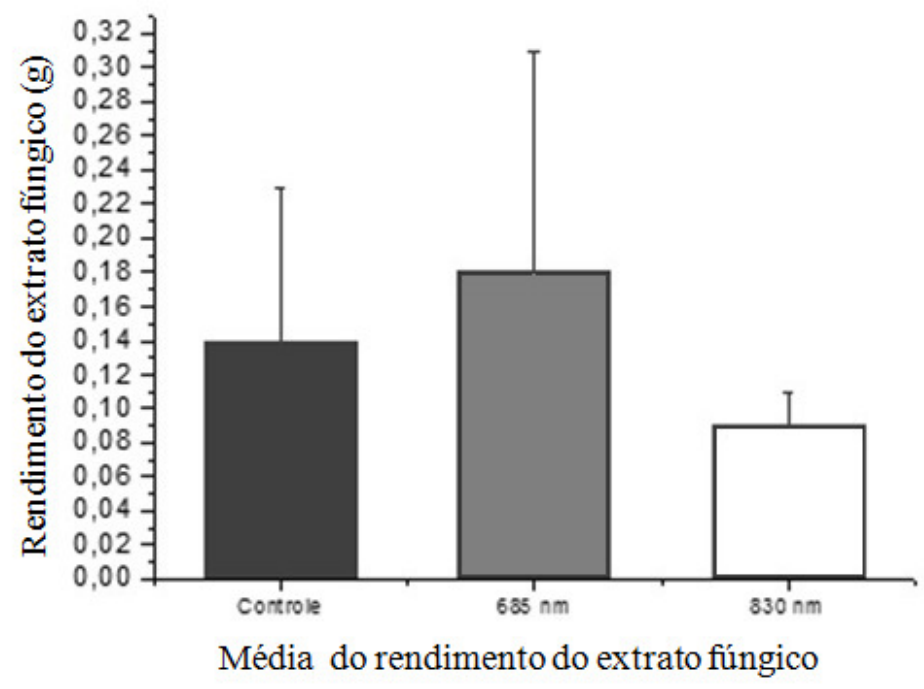

Fig. 4 - Rendimento do extrato fúngico. Rendimento do extrato fúngico. 0 extrato orgânico seco obtido de cada placa foi pesado e o resultado é apresentado como média e desvio padrão do resultado obtido de três placas de cada tratamento. Na comparação dos grupos, tratamentos com o controle $p>0,05$, sem significância estatística.

Após a pesagem dos extratos fúngicos secos, foi observado que o rendimento do extrato das placas irradiadas a $685 \mathrm{~nm}$, em média, foi $35,71 \%$ superior do que o do controle. Porém o rendimento dos extratos fúngicos das placas irradiadas a $830 \mathrm{~nm}$, em média, foi $35,71 \%$ inferior ao do controle (conforme Fig. 4). No entanto, essa diferença não foi estatisticamente significante $(p=0,3250)$.

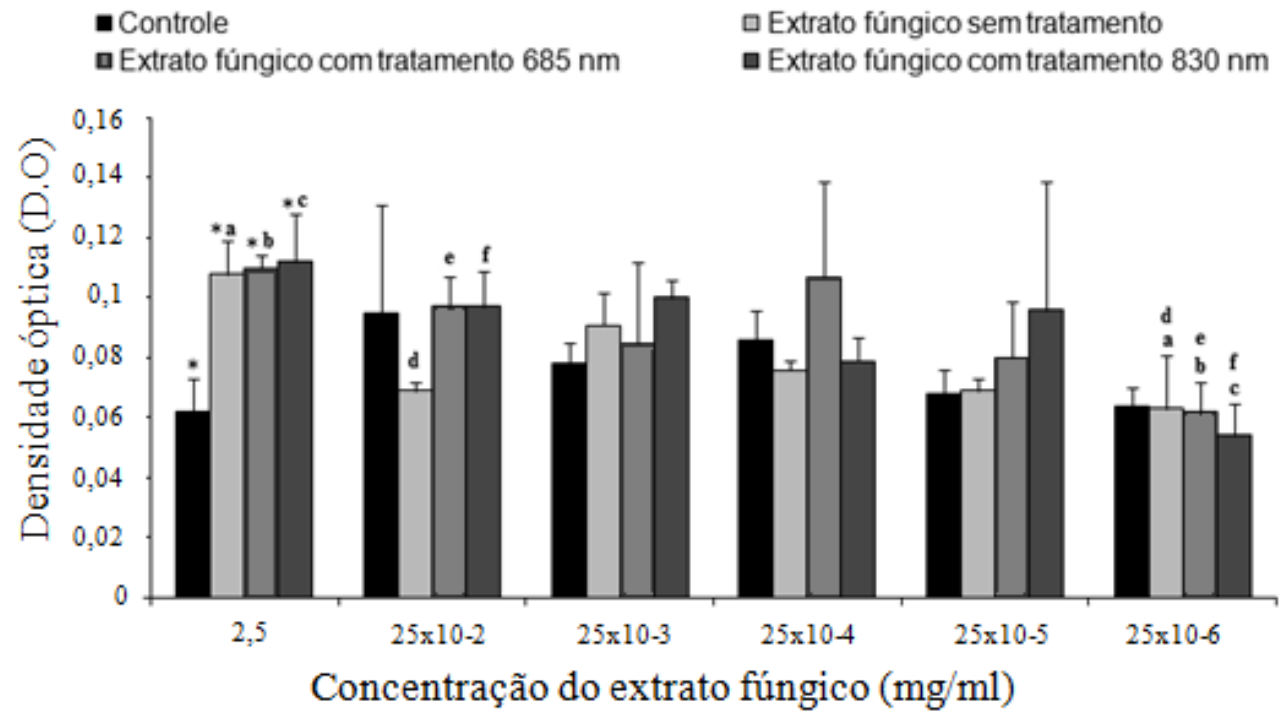

Fig. 5 - Concentração do extrato fúngico na atividade de enzimas mitocondriais de células L929 em cultura. Efeito da concentração do extrato fúngico na atividade de enzimas mitocondriais de células L929 em cultura. Média e desvio padrão de cada tratamento. Diferença estatística sinalizada com letras (vide Tabela 1). 
Tabela 1 - Diferença estatística da análise de atividade mitocondrial nas variações de concentração de extrato fúngico

\begin{tabular}{|c|c|c|}
\hline $\begin{array}{c}\text { Comparação da } \\
\text { concentração de extrato } \\
\text { fúngico }\end{array}$ & $\begin{array}{l}\text { Significância estatística } \\
\text { (Análise de Tukey) }\end{array}$ & Sinalização em letras na Fig. 5 \\
\hline $2,5 \mathrm{mg} / \mathrm{ml}$ & $p<0,01$ & $\begin{array}{l}\text { Controle comparado com os } \\
\text { demais grupos, sinalizados como: } \\
\text { a, b, c, na mesma concentração. }\end{array}$ \\
\hline $2,5 \mathrm{mg} / \mathrm{ml} \mathrm{e} 25 \times 10^{-6} \mathrm{mg} / \mathrm{ml}$ & $p<0,05$ & 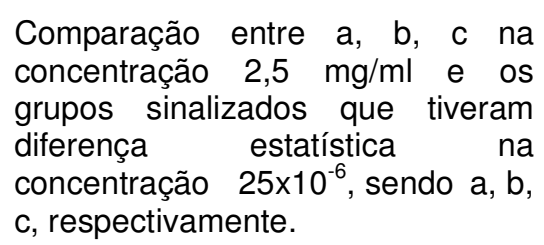 \\
\hline $\begin{array}{c}25 \times 10^{-2} \mathrm{mg} / \mathrm{ml} \text { e } 25 \times 10^{-6} \\
\mathrm{mg} / \mathrm{ml}\end{array}$ & $p<0,05$ & $\begin{array}{l}\text { Comparação entre d, e, f na } \\
\text { concentração } 25 \times 10^{-2} \mathrm{mg} / \mathrm{ml} \text { e os } \\
\text { grupos sinalizados que tiveram } \\
\text { diferença estatística na } \\
\text { concentração } 25 \times 10^{-6} \text {, sendo } d \text {, e, } \\
f \text {, respectivamente. }\end{array}$ \\
\hline
\end{tabular}

Com relação ao teste de citotoxicidade dos extratos fúngicos sobre células L929, as que não receberam qualquer extrato fúngico tiveram uma menor atividade mitocondrial, quando comparado com as células que receberam extratos fúngicos na concentração de $2,5 \mathrm{mg} / \mathrm{ml}$, com significância estatística $(p<0,01)$. No entanto, não houve diferença na atividade mitocondrial das células tratadas com os diferentes extratos, nessa concentração. Esse efeito diminui com a diminuição da concentração dos extratos fúngicos.

$\mathrm{Na}$ análise estatística comparativa da citotoxicidade causada pelos extratos nas concentrações $2,5 \mathrm{mg} / \mathrm{ml}$ e $25 \times 10^{-6} \mathrm{mg} / \mathrm{ml}$, obtive-se $p<0,05$, o mesmo ocorreu entre as concentrações $25 \times 10^{-2} \mathrm{mg} / \mathrm{ml}$ e $25 \times 10^{-6}$ $\mathrm{mg} / \mathrm{ml}$ (Tabela 1).

Foi possível, também, notar que, conforme as concentrações dos extratos aumentam, houve o aumento da atividade mitocondrial com uma hora de incubação.
$\mathrm{Na}$ concentração de $25 \times 10^{-2} \mathrm{mg} / \mathrm{ml}$, observou-se uma elevação considerável (78,55\%) na atividade mitocondrial dos grupos com tratamento, em relação ao controle e queda de atividade, após diminuir as concentrações, como pode ser verificado na Fig. 5. Observou-se um aumento da atividade mitocondrial quando utilizados os extratos fúngicos com tratamento laser diferente, do extrato fúngico sem tratamento, em que foi observada a diminuição da atividade mitocondrial, de $27,37 \%$, em relação ao controle na concentração, $25 \times 10^{-2} \mathrm{mg} / \mathrm{ml}$. Observou-se, ainda, um aumento da atividade mitocondrial das células com extrato fúngico com tratamento laser $830 \mathrm{~nm}$, na concentração $2,5 \mathrm{mg} / \mathrm{ml}$, sendo um aumento de $82,14 \%$, em relação ao controle.

\section{DISCUSSÃO}

No presente estudo, constatou-se que a utilização da luz laser de baixa 
intensidade, na irradiação do dermatófito filamentoso $T$. rubrum, resultou no aumento do crescimento do diâmetro das colônias, contradizendo os estudos de Vural et al. (2008) e Biscanin, Stipetic e Jerolimo (2005), em que a laserterapia resultou no efeito inibitório do crescimento celular das colônias fúngicas.

No estudo de Vural et al. (2008) foi descrito o crescimento de colônias de $T$. rubrum, irradiadas com laser em vários comprimentos de onda, nas doses de 4 e 8 $\mathrm{J} / \mathrm{cm}^{2}(1064 \mathrm{~nm})$ e $8 \mathrm{~J} / \mathrm{cm}^{2}$ (532 nm), obtidas do laser de Nd:YAG, e isso promoveu um efeito inibitório de crescimento das colônias. Neste estudo foi aplicada a irradiação da luz laser em comprimentos de onda na mesma faixa de espectro (infravermelho e vermelho visível), porém em diferente densidade de energia, podendo-se, então, inferir que a densidade de energia pode ter sido responsável pela discrepância de resultados.

Biscanin, Stipetic e Jerolimo (2005) descreveram 0 estudo do efeito da laserterapia de baixa intensidade no crescimento de Candida albicans e inflamação palatal em dois pacientes com estomatite por dentadura. Ambos os pacientes foram irradiados na mucosa palatal e na base acrílica da dentadura, com tempo de 5 minutos de exposição (830 nm, $3,0 \mathrm{~J} / \mathrm{cm}^{2}, 60 \mathrm{~mW}$ ) e tempo de 10 minutos $\left(685 \mathrm{~nm}, 3,0 \mathrm{~J} / \mathrm{cm}^{2}, 30 \mathrm{~mW}\right)$, por 5 dias consecutivos. Avaliou-se, por intermédio do método de swab e estimação semiquantitativa do crescimento das colônias em placa com ágar. A inflamação foi avaliada conforme resposta clínica. Após o término do tratamento, ocorreu a diminuição das colônias e da inflamação. Há relatos, na literatura, sobre os efeitos do laser na melhora do quadro de inflamação, porém ainda são poucos estudos sobre o efeito da luz laser em microrganismos sem a utilização de um fotossensibilizador. Biscanin, Stipetic e Jerolimo (2005) apresentaram resultados promissores, no tratamento de lesões fúngicas causadas por Candida albicans, com laserterapia, mas, ainda, fazem-se necessários estudos que validem essa técnica para o tratamento de lesões causadas por outras cepas fúngicas.

Os estudos de Vural et al. (2008) e Biscanin, Stipetic e Jerolimo (2005) demonstraram que laser de baixa intensidade tem ação no metabolismo celular de microrganismos, inibindo o seu crescimento. Porém não há definição criteriosa, na literatura, sobre a definição de protocolos de utilização da laserterapia de baixa intensidade no tratamento de feridas infectadas que podem ser causadas pelo $T$. rubrum.

Além de acompanhar o crescimento fúngico após a irradiação da luz laser em dois comprimentos de onda diferentes, avaliou-se o efeito dos metabolitos fúngicos, produzidos após a irradiação com laserterapia, nas células L929. Nesse experimento, foi observado um aumento significativo da atividade mitocondrial das células incubadas com extrato fúngico com tratamento laser, em relação ao controle. $O$ estudo de Holt et al. (1988), envolvendo metabólitos secundários em cultura de células L929, apresentou uma inibição da atividade mitocondrial. Pode-se inferir, então, que a irradiação com laser de baixa intensidade nas colônias fúngicas resultou um efeito na produção de metabólitos secundários, pois estes ao ensaiados nas células L929, promoveu uma estimulação da atividade mitocondrial. 
Fernandes et al. (2009) relataram um estudo sobre a ação de metabólitos secundários de fungos endofíticos contra bactérias gram positivas, gram negativas $\mathrm{e}$ leveduras, também foi testada a ação antitumoral. Em conclusão, os autores descreveram que esses metabólitos podem ser uma fonte promissora de compostos bioativos. Ainda assim, são necessários mais estudos que descrevam a ação dos metabólitos secundários de fungos e possíveis aplicações clínicas.

Evidenciou-se, neste estudo, a importância de maiores estudos sobre a ação da fototerapia em microrganismos e a elaboração de protocolos clínicos seguros para o uso do laser de baixa intensidade, para o tratamento de dermatomicoses.

\section{CONCLUSÕES}

O laser de baixa intensidade GaAlAs, nas condições metodológicas, apresentou efeitos no metabolismo celular do T. rubrum, como a alteração de morfologia e da taxa de crescimento da colônia in vitro.

Em relação aos metabólitos secundários, foi observado, após o processo de extração, que o maior rendimento foi obtido das placas irradiadas a $685 \mathrm{~nm}$ e 0 menor rendimento foi obtido das placas irradiadas a $830 \mathrm{~nm}$, quando comparado com o rendimento das placas controle.

O extrato fúngico das colônias irradiadas promoveu efeito bioestimulador em células L929, quando comparado ao grupo controle sem tratamento laser.

\section{AGRADECIMENTOS}

À Profa. Dra. Sônia Khouri Crosariol, do Laboratório de Microbiologia da Universidade do Vale do Paraíba, que gentilmente, cedeu as cepas fúngicas.

Á Fundação Vale Paraibana de Ensino (FVE) e à Coordenação de Aperfeiçoamento de Pessoal de Nível Superior (CAPES), pelo apoio financeiro.

\section{REFERÊNCIAS}

ALY, R.; HAY, R. J.; DEL PALACIO, A.; GALIMBERTI, R. Epidemiology of Tinea capitis. Med Mycol, v. 38, p.183-188, 2000.

ARENAS, R.; DOMINGUEZ-CHERIT, J.; FERNANDEZ, L. M. Open randomized comparison of itraconazole versus terbinafine in onychomycosis. Int J Dermatol, v. 34, p.138-143, 1995.

AMAN, S. et al. Tinea unguium in Lahore, Pakistan. Med Mycol, v. 39, p.177-180, 2001.

BISCANIN, M. M.; STIPETIC, M. M.; JEROLIMO, V. Effect of Low-Level Laser Therapy on Candida albicans Growth in Patients with Denture Stomatitis. Photomedicine and Laser Surgery, v. 23, n. 3, p. 328-332, 2005.

BORATO, E. et al. Avaliação imediata da dor e edema em lesão muscular induzida por formalina e tratada com laser $808 \mathrm{~nm}$. Revista Brasileira de Medicina e Esporte, v. 14, n.5, p.446-449, 2008.

CERVELATTI, E. P. et al. Electrophoretic molecular karyotypeof the dermatophyte Trichophyton rubrum. Genetic and Molecular Biology, v. 27, n. 1, p. 99-102, 2004.

ELEWSKI, B. E. Onychomycosis. Treatment, quality of life, and economic issues. Am J Clin Dermatol, v. 1, p.19-26, 2000. 
Tinea capitis: a current médica, São Paulo: Sarvier, 2002, p. 303perspective. J Am Acad Dermatol, v. 42, p. 1- 304.

20, 2000.

FERNANDES, M. R. V. et al. Biological activities of the fermentation extract of the endophytic fungus Alternaria Alternata isolated from Coffea arabica L. Brazilian Journal of Pharmaceutical Sciencies, v. 45, n. 4, p. 677-685, 2009.

FINCH, J. J.; WARSHAW, E. M. Toenail onychomycosis: Current and future treatment options. Dermatol. Ther., v. 20, p. 31-46, 2007.

GUPTA, A. K. et al. Detection of Xanthomegnin in Epidermal Materials Infected with Trichophyton rubrum. J. Invest Dermatol, v. 115, p. 901-905, 2000.

HEES, H.; RAULIN, C.; BAUMLER, W. Laser treatment of onychomycosis: an in vitro pilot study, JDDG, v. 10, p. 1-5, 2012.

HOLT, P. S. et al. Cytotoxic effect of T-2 mycotoxin on cells in culture as determined by a rapid colorimetric bioassay. Toxicon, $v$. 26, p. 549-558, 1988.

JOISH, V. N; ARMSTRONG, E. P. Which antifungal agent for onychomycosis? A pharmacoeconomic analysis. Pharmacoeconomics, v. 19, p.983-1002, 2001.

KOEHLER, A. M.; MAIBACH, H. I. Electronic monitoring in medication adherence measurement. Implications for dermatology, Am J Clin Dermatol, v. 2, p. 7-12, 2001.

KOZAREV, J.; VIZINTIN, Z. Novel laser therapy in treatment of onychomycosis. Journal of the Laser and Health Academy, v. 1, p. 1-8, 2010.

LACAZ, C. S. et al. Tratado de microbiologia
LACAZ, C. S.; PORTO, E.; MARTINS, J. E. C. Micologia Clínica: Dermatófitos, 8. ed., São Paulo: Brasil, 1991, p. 120-160.

LESHER, J. L. JR. Oral therapy of common superficial fungal infections of the skin. J Am Acad Dermatol, v. 40, p. S31-S34, 1999.

MANEVITCH, Z. et al. Direct antifungal effect of femtosecond laser on Trichophyton rubrum onychomycosis, Photochem Photobiol, v. 86, n. 2, p. 476-9, 2010.

MARCHISIO, F. V.; PREVE, L.; TULIO, V. Fungi responsible for skin mycoses in Turin (Italy), Mycoses, v. 39, n. 3-4, p. 141-150, 1996.

NWEZE, E. I. Etiology of dermatophytoses amongst children in northeastern Nigeria. Med Mycol, v. 39, p. 181-184, 2001.

REZENDE, C. et al. Estudo epidemiológico das dermatofitoses em instituições públicas da cidade de Barretos, São Paulo, Brasil. Revista Brasileira de Análises Clínicas, v. 40, n. 1, p. 13-16, 2008.

ROCHA, J. C. T. Terapia laser, cicatrização tecidual e angiogenese. Revista Brasileira de Promoção de Saúde, Fortaleza-CE, $2003 . \quad$ Disponível em: http://www.unifor.br/hp/revista_saude/v17-

1/artigo8.pdf. Acesso em: 24 nov. 2011.

RODRIGUES, E. R. Estudo da ação de extratos vegetais de Pothomorphe umbellata e Drogas antifúngicas sobre linhagens de Trichophyton rubrum e análise da expressão proteica. 2007. Dissertação de Mestrado em Biotecnologia da UNAERP, Ribeirão Preto, 2007.

SABINO, M.; INOMATA, E. I.; LAMARCO, L. 
C. A. Variação dos níveis de aflatoxina B1 em pasta de amendoim e paçoca consumidas no estado de São Paulo. Revista Instituto Adolfo Lutz, v. 42, n. 1/2, p. 39-44, 1982.

SANTOS, C. C. G.; SAMPAIO, E. A. P.; PINHEIRO, N. B. Fatores de virulência do gênero Trichophyton, 2006. Disponível em: http://www.medstudents.com.br/content/resu mos/resumo_medstudents_20070131_04.do c. Acesso em: 11 ago. 2009.

SCHER, R. K. Onychomycosis: therapeutic update. J Am Acad Dermatol, v. 40, p. S21S26, 1999.

SIGURGEIRSSON, B. et al. Long-term effectiveness of treatment with terbinafine vs itraconazole in onychomycosis: A 5-year blinded prospective follow-up study. Arch. Dermatol, v. 138, p. 353-357, 2002.

SILVEIRA, M. V.; NICOLAU, R. A. Efeito analgésico em afecções músculoesquelético pós-terapia com laser operando em baixa potência - revisão de literatura, IN: XI Encontro Latino Americano de Iniciação Científica e VII Encontro Latino Americano de Pós-Graduação - Universidade do Vale do Paraíba, 2007, São José dos Campos, SP. Anais eletrônicos, São Paulo: UNIVAP, 2007, p. 2019-2022. Disponível em: http://www.inicepg.univap.br/l

NIC_07/trabalhos/saude/epg/EPG00 388_010.pdf. Acesso em: 07 maio 2009.

TOSTI, A. et al. Relapses of onychomycosis after successful treatment with systemic antifungals: A three-year follow-up. Dermatology, v. 197, p.162-166, 1998.

TRABULSI, L. R.; TRABULSI (ED), L.R.; ALTHERTUM, F. Microbiologia. 3. ed. São Paulo: Atheneu, 1999, p. 586.

VIEIRA, S. Introdução à bioestatística. 2. ed. Rio de Janeiro: Campus, 1991. 203p.

VURAL, E. et al. The effects of laser irradiation on Trichophyton rubrum growth. Lasers Medical Science, v. 23, p. 348-353, 2008.

WEITZMAN, I.; SUMMERBELL, R. C. The Dermatophytes. Clin Microbiol Rev., v. 8, p. 240-259, 1995.

ZAITZ, C. et al. Compendio de Micologia Médica. Rio de Janeiro: Médica e Científica Ltda., 1998, p. 65-7. 